\title{
Fluid volume used for medication delivery in critically ill adults
}

\author{
Teegan Ignacy, PharmD, RPh, ACPR (1) - Stephanie Carlin, PharmD, \\ RPh, ACPR $\cdot$ Mark Duffett, PhD, RPh
}

Received: 17 August 2020/Revised: 24 November 2020/Accepted: 25 November 2020/Published online: 6 January 2021

(C) Canadian Anesthesiologists' Society 2021

\section{To the Editor,}

Intravenous (IV) fluids are a ubiquitous component of care in the intensive care unit (ICU), but fluid overload is associated with increased mortality. The contribution of IV fluids to medication delivery has not been well characterized. Our objectives were to 1) determine the volume of fluids used to deliver medications, 2) describe how fluid administration changed over patients' stay in ICU, and 3) elucidate opportunities for reduction of medication fluid volumes.

This historical cohort study included 50 randomly selected patients admitted for more than $24 \mathrm{hr}$ to either of two adult ICUs in a tertiary academic centre (1 July to 31 October 2016). Results are described using percentage and median [interquartile range]. Linear regression was applied to assess changes in fluid over time.

Patients were 59 [51-70] yr of age and stayed in the ICU for 3 [1-6] days. Patients received 12.5 [7.0-18.4] L of total fluid during their ICU stay ranging from 0.7 to $55.0 \mathrm{~L}$. Medication fluids comprised 1.7 [0.8-3.0] $\mathrm{L}$ and this varied

T. Ignacy, PharmD, RPh, ACPR ( $\square)$

Department of Pharmacy, Michael Garron Hospital, Toronto

East Health Network, Toronto, ON, Canada

e-mail: teegan.ignacy@tehn.ca

S. Carlin, PharmD, RPh, ACPR

Department of Pharmacy, Hamilton Health Sciences, Hamilton, ON, Canada

M. Duffett, PhD, RPh

Department of Pharmacy, Hamilton Health Sciences, Hamilton, ON, Canada

Departments of Pediatrics and Health Research Methods, Evidence, and Impact, McMaster University, Hamilton, ON, Canada from 0.05 to $8.0 \mathrm{~L}$. The percentage of fluids from medications was 18 [11-29]\% and varied from 6 to $81 \%$. The Figure shows the types of fluids as a percentage of the total fluids for all patients.

Patients received 2.5 [1.3-3.8] L of fluid per day with the largest volume given on their first day of admission (4.0 [2.8-6.3] L), which decreased over time by a mean of 239 $\mathrm{mL} \cdot$ day $^{-1}$ (95\% confidence interval $[\mathrm{CI}], 161$ to $318 ; P<$ 0.001). Similarly, patients received 0.5 [0.2-0.9] $\mathrm{L}$ of medication fluid per day with the largest volume of fluid given on day one (0.7 [0.4-1.0] L), which decreased over time by a mean of $42 \mathrm{~mL} \cdot \mathrm{day}^{-1}(95 \% \mathrm{CI}, 15$ to $69 ; P=$ $0.01)$. While the total volume decreased, the percentage of fluids from medication did not change significantly from day to day $(19[13-21] \%)$. The anatomical therapeutic chemical medication class contributing most to medication fluids was anti-infectives, making up $37 \%$ of all medication fluid. For the three most common antibiotics used (vancomycin, piperacillin-tazobactam, and cefazolin), we consulted three drug information resources (The Ottawa Hospital Manual, Thompson Micromedex ${ }^{\circledR}$ Healthcare Series, and Pediatric Injectable Drugs) to determine the maximum studied concentrations. ${ }^{1-3}$ We found that volumes of vancomycin, piperacillin-tazobactam, and cefazolin could be reduced by $53 \%, 77 \%$, and $70 \%$ from the most common current volumes given, respectively.

Our data are generally consistent with similar studies. Silversides et al. enrolled patients in ten ICUs in Canada and the United Kingdom and found $35 \%$ of fluids administered in the first three days were from medications. ${ }^{4}$ Fuhrman et al. studied critically ill children in a single centre in the United States and found that medications were responsible for $29 \%$ of total fluid consumption. The percentage was higher $(34 \%)$ in fluid overloaded patients and the authors hypothesized that 


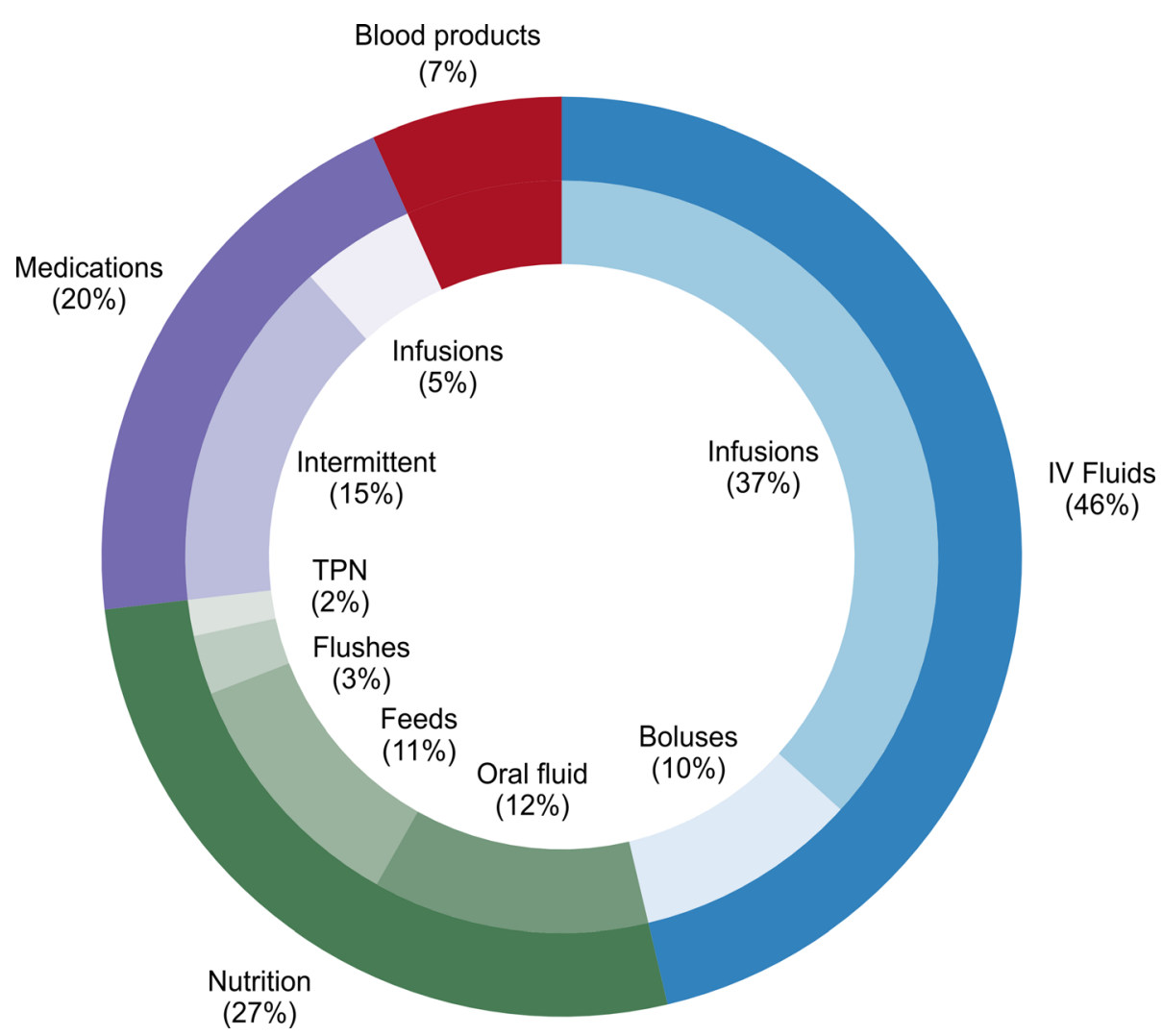

Figure Contribution of each fluid type to the total fluids administered to patients in the intensive care unit

medication fluids may be a source that is not reduced when patients become fluid overloaded. ${ }^{5}$

We recognize that reducing medication fluid may not be feasible in all centres. While some changes may have little impact on costs and processes, others may require in-house compounding and additional resources. Availability of multiple drug concentrations increases the risk of errors; therefore, the sole adoption of higher concentrations of some medications may be warranted. Chosen fluids and concentrations are based in part on the stability and safety profile of each agent; however, the negative effects of excess fluid administration should also inform decisionmaking.

Future research should focus on patients at higher risk of fluid overload (i.e., patients with renal failure and heart failure) with outcome data to determine whether reducing medication fluids has a meaningful impact on patient morbidity and mortality.

\section{Disclosures None.}

Funding statement None.
Editorial responsibility This submission was handled by Dr. Alana M. Flexman, Associate Editor, Canadian Journal of Anesthesia.

\section{References}

1. The Ottawa Hospital. The Ottawa Hospital Parental Drug Therapy Manual, 36th Edition. 2015.

2. IBM Micromedex ${ }^{\circledR}$. Drug Information. (Hamilton Health Sciences Library). Available from URL: http://www.micromedexsolutions. com/ (accessed December 2020).

3. Phelps SJ, Hagemann TM, Lee KR. The Teddy Bear Book: Pediatric Injectable Drugs, $10^{\text {th }}$ Edition. American Society of Health-System Pharmacists; 2013.

4. Silversides JA, Fitzgerald E, Manickavasagam US, et al. Deresuscitation of patients with iatrogenic fluid overload is associated with reduced mortality in critical illness. Crit Care Med 2018; 46: 1600-7.

5. Fuhrman D, Crowley K, Vetterly C, Hoshitsuki K, Koval A, Carcillo J. Medication use as a contributor to fluid overload in the PICU: a prospective observational study. J Pediatr Intensive Care 2018; 7: 69-74.

Publisher's Note Springer Nature remains neutral with regard to jurisdictional claims in published maps and institutional affiliations. 